\title{
Evidence of Psychological Targeting but not Psychological Tailoring in Political Persuasion Around Brexit
}

\author{
Christopher Walker ${ }^{1, *}$ (D), Stephen O'Neill ${ }^{2}$ and Lee de-Wit ${ }^{3}$ \\ ${ }^{1}$ Position: Former Masters student at UCL; Qualifications: MA, MSc., ${ }^{2}$ Position: Former Masters student at UCL; Qualifications: \\ BA, MSc., and ${ }^{3}$ University Lecturer, University of Cambridge. \\ ${ }^{*}$ Corresponding author: c.walker.17@alumni.ucl.ac.uk
}

(Received 28 January 2020; Revised 02 July 2020; Accepted 10 August 2020)

\begin{abstract}
There are numerous associations between psychological characteristics and political values, but it is unclear whether messages tailored to these psychological characteristics can influence political decisions. Two studies ( $N=398, N=395)$ tested whether psychological-based argument tailoring could influence participants' decision-making. We constructed arguments based on the 2016 Brexit referendum; Remain supporters were presented with four arguments supporting the Leave campaign, tailored to reflect the participant's strongest (/weakest) moral foundation (Loyalty or Fairness) or personality trait (Conscientiousness or Openness). We tested whether individuals scoring high on a trait would find the tailored arguments more persuasive than individuals scoring low on the same trait. We found clear evidence for targeting, particularly for Loyalty, but either no evidence or weak evidence, in the case of Conscientiousness, for tailoring. Overall, the results suggest that targeting political messages could be effective, but provide either no, or weak evidence that tailoring these messages influences political decision-making.
\end{abstract}

\section{Introduction}

Adverts targeted and tailored to psychological traits have been shown to be effective in non-political domains (Matz et al., 2017). Given the alleged roles of Cambridge Analytica and AggregateIQ in recent political campaigns, the question of whether psychologically tailored and targeted arguments are effective in political contexts has important social implications ${ }^{1}$.

Research has demonstrated that personal and moral values reliably correlate with political decisions in the US and UK (Gerber et al., 2010; Graham et al., 2009; Sibley et al., 2012) and so targeting and tailoring arguments in line with these values could be effective. In addition to the research showing the effectiveness of personality-based tailoring in advertising (Hirsh et al., 2012; Matz et al., 2017), there is some evidence that Moral Foundations Theory (MFT) can be effective in tailoring political arguments (Feinberg \& Willer, 2013; 2015; Voelkel \& Feinberg, 2018), although the combined role of tailoring and targeting based on individual

\footnotetext{
${ }^{1}$ Tailoring refers to the matching of one's psychological characteristics with phrases used in discourse in an attempt to persuade- in this study, the tailored vs control arguments comparison assesses tailoring. Targeting refers to presenting discourse to those who's psychological characteristic most closely aligns with the position of the discourse - in this study, the high vs low group comparison assesses targeting.
} 
differences in Moral Foundations has not been tested. Moreover, while some longitudinal research has suggested an influence of personality on political decisions over time (Ekstrom \& Federico, 2019) the exact role personality plays within political decision-making is still under debate (Hatemi et al., 2014).

Overall, the efficaciousness of psychologically tailored arguments and psychological targeting remains largely untested within the political domain while the causal influence of psychological constructs like Personality and Moral Foundations in political decision-making requires further investigation.

\section{Objective}

To investigate psychological-based argument targeting and tailoring, and the potential causal influence of personality and moral foundations in political decision-making, this study sought to test four hypotheses ${ }^{2}$ in terms of the targeting and tailoring of arguments for Leaving the European Union:

1. In-group loyalty tailored arguments will be more effective for Remain-supporting voters who are high on the Moral Foundation of Ingroup Loyalty.

2. Fairness tailored arguments will be more effective for Remain-supporting voters who are high on the Moral Foundation of Fairness.

3. Openness tailored arguments will be more effective for Remain-supporting voters who are high on the personality trait Openness.

4. Conscientiousness tailored arguments will be more effective for Remain-supporting voters who are high on the personality trait Conscientiousness.

Loyalty and Fairness (study 1) were chosen because they had previously been effective in moral framing research in the US, with Loyalty particularly appealing to conservatives, and Fairness to liberals (Voelkel \& Feinberg, 2018). Openness and Conscientiousness (study 2) were chosen because, of the big 5 personality traits, they have shown the most robust links to liberal and conservative political attitudes respectively (Gerber et al., 2010).

\section{Methods}

\section{Study 1 - Moral Foundations}

398 Remain supporting participants ${ }^{3}$ undertook an abbreviated $^{4}$ Moral Foundations Questionnaire (MFQ) and received MFT-based arguments tailored to the foundations of Loyalty or Fairness.

The research design was mixed; there was one independent variable, message tailoring with two levels - tailored or control. To ensure participants were assigned to the condition reflecting their most (or least) dominant trait, participants first completed a Moral Foundations questionnaire measuring their Loyalty and Fairness. Two standardised z-scores - one for each trait - were created for each participant ${ }^{5}$. Participants were then assigned to read either the Loyalty or Fairness arguments based on their most extreme (highest or lowest) z-score, to maximise the power of the design. Those in the Loyalty condition received arguments tailored to high Loyalty, and a non-tailored control, whilst those in the Fairness condition received arguments tailored to high Fairness and a non-tailored control.

After the Moral Foundation Questionnaire participants read four counter-attitudinal arguments: three MFT tailored arguments and one non-tailored control. The control argument was included to test the causal influence of argument tailoring on decision-making; participants high $v s$. low on Loyalty and Fairness are not expected to rate a non-tailored control any differently.

\footnotetext{
${ }^{2}$ https://osf.io/fd $29 \mathrm{~m} /$

${ }^{3}$ See Methodology addendum for full recruitment details.

${ }^{4}$ Both MFQ and BFI were shortened such that participants only answered the questions pertaining to Loyalty $(\alpha=.68)$ and Fairness $(\alpha=.60)$ and Conscientiousness $(\alpha=.84)$ and Openness, $(\alpha=.81)$ respectively.

${ }^{5}$ Based on participant's own score on each trait in addition to world average (UK average for Study 2 ) and standard deviation for each trait.
} 
After each argument participants were asked three questions about the argument, two measuring their attitude to the argument (argument credibility and argument compellingness) and one measuring behavioural intentions (intention to vote for a party making this argument) on a scale from 0 to $10^{6}$.

Prior to the analysis, and for analysis purposes, participants were assigned to a high or low Loyalty (/Fairness) group based on the average Loyalty (/Fairness) score in the sample. Those with scores less than or equal to the average were considered low.

A similar study with Leave supporting participants was discontinued due to a small sample size $(N=83)$.

\section{Study 2 - Personality}

A second study following the exact same procedure was conducted to assess the effect of personalitybased argument tailoring. 395 Remain supporting participants undertook an abbreviated Big Five Inventory questionnaire (B-5) and received personality-based arguments tailored to the traits of Conscientiousness and Openness.

Again, a study investigating Leave supporting participants was discontinued due to a small sample size $(N=65)$.

\section{Analysis Strategy}

Given the mixed design, the primary statistical interest was the interaction effect between the high and low groups across the tailored and control arguments. To analyse these effects, we conducted two-way mixed ANOVA $^{7}$ models. These models assessed the between impact of moral foundation (/personality) group (high $v s$. low), the within impact of argument type (tailored $v s$. control) and the interaction effect on the argument scores. Given paired comparisons were performed separately for the three rating measures (credible, compellingness, vote intention), for simplicity these were combined for the ANOVA models.

The secondary interest was a between-subjects test of whether participants high on a given moral foundation (/personality) trait rated the arguments differently from those low on the same trait. To assess these paired comparisons independent t-tests were conducted across each of the three rating measures ${ }^{8}$. Given participants rated the arguments on three separate dependent variables - Credibility, Compellingness and Vote - the statistical threshold for the paired comparisons was controlled using the Holm-Bonferroni correction. All p-values reported for the independent t-tests are two-sided.

Whilst the distributions were not normal, the sample sizes were considered sufficiently large to conduct both two-way mixed ANOVAs and independent t-tests.

\section{Results}

\section{Study 1 - Moral Foundations}

\section{Loyalty condition}

Two-way mixed ANOVA results showed a significant main effect of group on argument scores $F$ $(1,1,172)=302.96, p<.001, \eta_{\mathrm{p}}{ }^{2}=.21$. There was also a significant main effect of argument type on argument scores $F(1,1,172)=14.97, p<.001, \eta_{\mathrm{p}}{ }^{2}=.013$. However, there was no significant interaction effect for Loyalty, $F(1,1,172)=.0001, p=.99, \eta_{\mathrm{p}}^{2}<0.001$.

\footnotetext{
${ }^{6}$ See Dependent variables for full details.

${ }^{7}$ The focus on a 2x2 Mixed ANOVA was a post-hoc decision that deviates from our pre-registration report. The use of this analysis was based on the unexpected findings across the control conditions and guidance from our reviewers. Whilst paired comparisons were performed separately for the three rating measures (credible, compelling, vote intention), for simplicity these were combined for the ANOVA.

${ }^{8} \mathrm{We}$ had preregistered that we would test whether the attitude measures (credibility and compellingness) mediated any differences in vote intention, but we decided instead to include this as another outcome measure. To control for the potential for false positives this might introduce, we applied a correction for three comparisons.
} 


\section{Argument Rating across High and Low Loyalty Conditions}

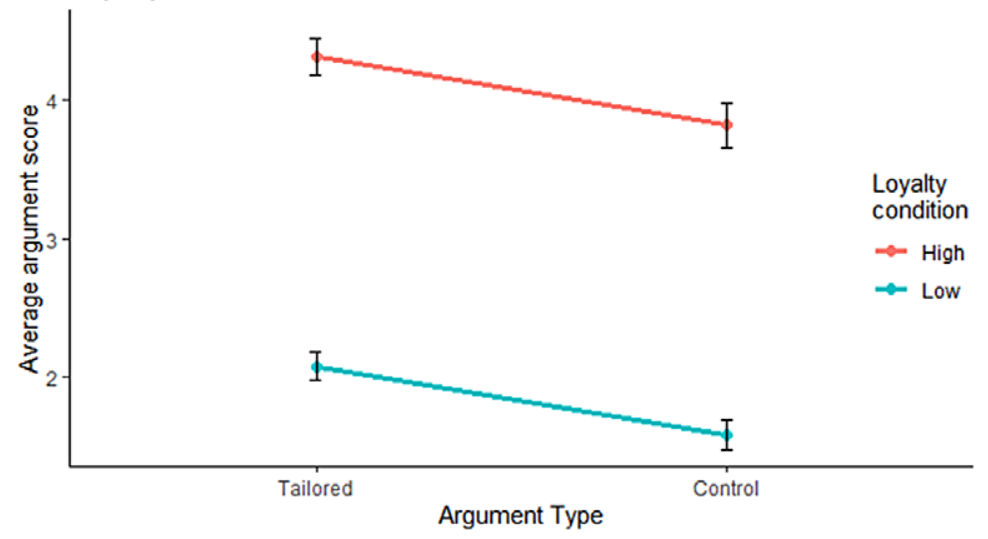

Walker Fig 1. - Mean argument rating of high and low Loyalty groups across the tailored and non-tailored arguments. (Error bars denote standard errors).

To investigate the between-subjects effects across the arguments independent t-tests were conducted. Independent t-tests indicated that individuals high on Loyalty significantly differed from those low on Loyalty across the tailored arguments. Those high on Loyalty found the arguments, more credible, $t(200.57)=6.35, p<.001, d=.89$, more compelling, $t(177.84)=8.63, p<.001, d=1.5$ and showed a greater intention to vote, $t(169.6)=8.63, p<.001, d=1.58$ than those low on Loyalty.

This pattern of significant differences between those high and low on Loyalty was also evident across the non-tailored control argument. Those high on Loyalty found the argument more credible, $t(199.29)=4.83, p<.001, d=.68$, more compelling, $t(169.27)=6.54, p<.001, d=1.2$ and showed a greater intention to vote, $t(155.78)=6.49, p<.001, d=1.33$ than those low on Loyalty.

\section{Fairness condition}

Two-way mixed ANOVA results showed a significant main effect of group on argument scores, $F$ $(1,1,058)=32.28, p<.001, \eta_{\mathrm{p}}{ }^{2}=.03$. There was also a significant main effect of argument type on argument scores $F(1,1,058)=64.98, p<.001, \eta_{\mathrm{p}}{ }^{2}=.06$. There was no significant interaction effect for Fairness, $F(1,1,058)=2.86, p=.09, \eta_{\mathrm{p}}{ }^{2}=0.003$.

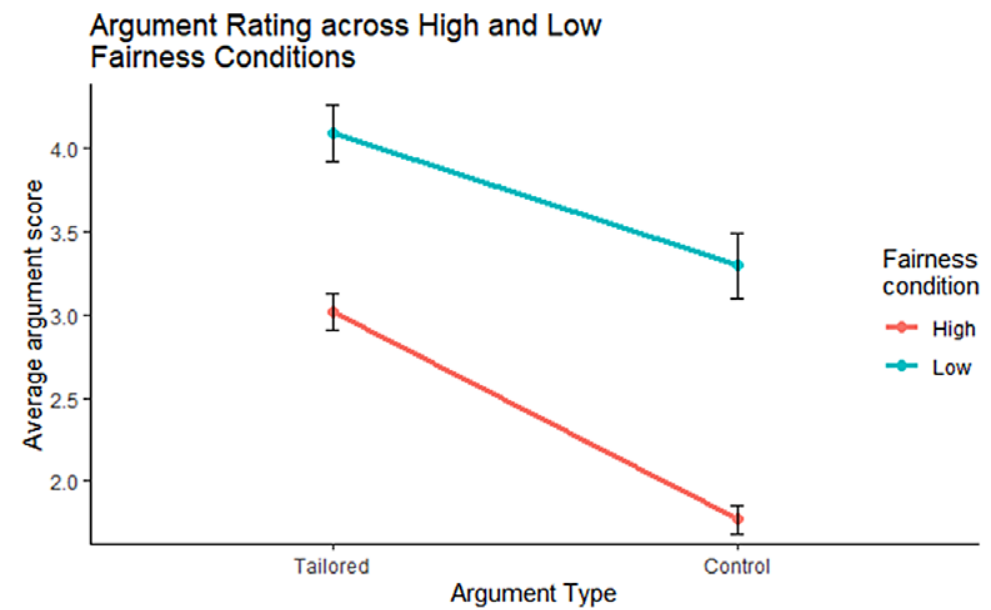

Walker Fig 2. - Mean argument rating of high and low Fairness groups across the tailored and non-tailored arguments. (Error bars denote standard errors). 
Independent t-tests indicated that individuals high on Fairness significantly differed from those low on Fairness across the tailored arguments. Those low on Fairness found the arguments, more credible, $t(110.17)=-2.16, p=.03, d=-.34$, more compelling, $t(101.92)=-3.33, p<.01, d=-.54$ and showed a greater intention to vote, $t(99.04)=-3.42, p<.001, d=-.56$ than those high on Fairness.

This pattern of significant differences between those high and low on Fairness was also evident across the non-tailored control argument. Those low on Fairness found the argument more credible, $t(98.71)=-2.81, p<.01, d=-.46$, more compelling, $t(90.82)=-3.34, p<.01, d=-.49$ and showed a greater intention to vote, $t(82.01)=-3.3, p<.01, d=-.47$ than those high on Fairness.

\section{Study 2 - Personality}

\section{Conscientiousness condition}

Two-way mixed ANOVA results showed a significant main effect of group on argument scores, $F(1,1,166)=16.18, p<.001, \eta_{\mathrm{p}}{ }^{2}=.014$. There was also a significant main effect of argument type on argument scores, $F(1,1,166)=12.78, p<.001, \eta_{\mathrm{p}}{ }^{2}=.011$. There was a marginally non-significant interaction effect for Conscientiousness, $F(1,1,166)=3.41, p=.065, \eta_{\mathrm{p}}{ }^{2}=0.003$.

\section{Argument Rating across High and Low Conscientiousness Conditions}

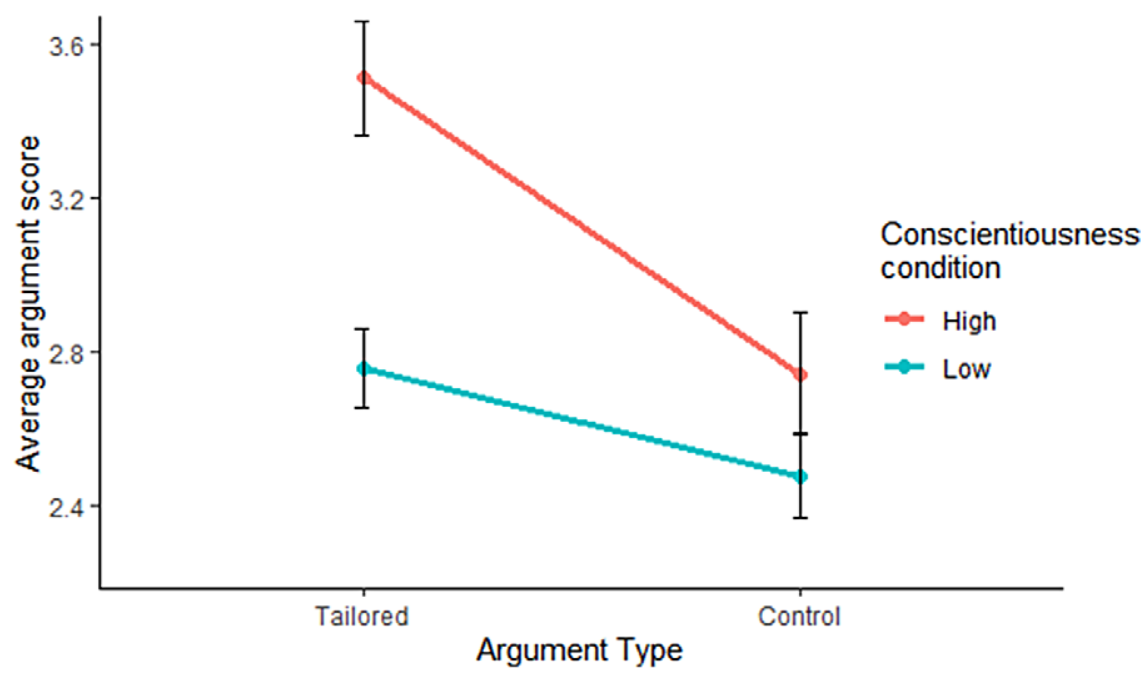

Walker Fig 3. - Mean argument rating of high and low Conscientiousness groups across the tailored and non-tailored arguments. (Error bars denote standard errors).

Independent t-tests indicated that individuals high on Conscientiousness significantly differed from those low on Conscientiousness across the tailored arguments. Those high on Conscientiousness found the arguments, more credible, $t(145.93)=2.00, p=.048, d=.3$, more compelling, $t(135.12)=2.33$, $p=.021, d=.35$ and showed a greater intention to vote, $t(131.05)=2.56, p=.01, d=.39$ than those low on Conscientiousness.

There were no significant differences across the non-tailored control argument: credibility, $t(137.49)=.81, p=.42, d=.12$, compellingness, $t(134.97)=.50, p=.62, d=.07$ and vote intention $t(128.39)=1.05, p=.30, d=.16$. 


\section{Openness condition}

Two-way mixed ANOVA results showed no significant main effect of group on argument scores, $F(1,1,136)=3.15, p=.076, \eta_{\mathrm{p}}{ }^{2}=.003$. There was a significant main effect of argument type on argument scores, $F(1,1,136)=19.95, p<.001, \eta_{\mathrm{p}}{ }^{2}=.02$. There was no significant interaction effect for Openness, $F(1,1,136)=2.45, p=.12, \eta_{\mathrm{p}}{ }^{2}=0.002$.

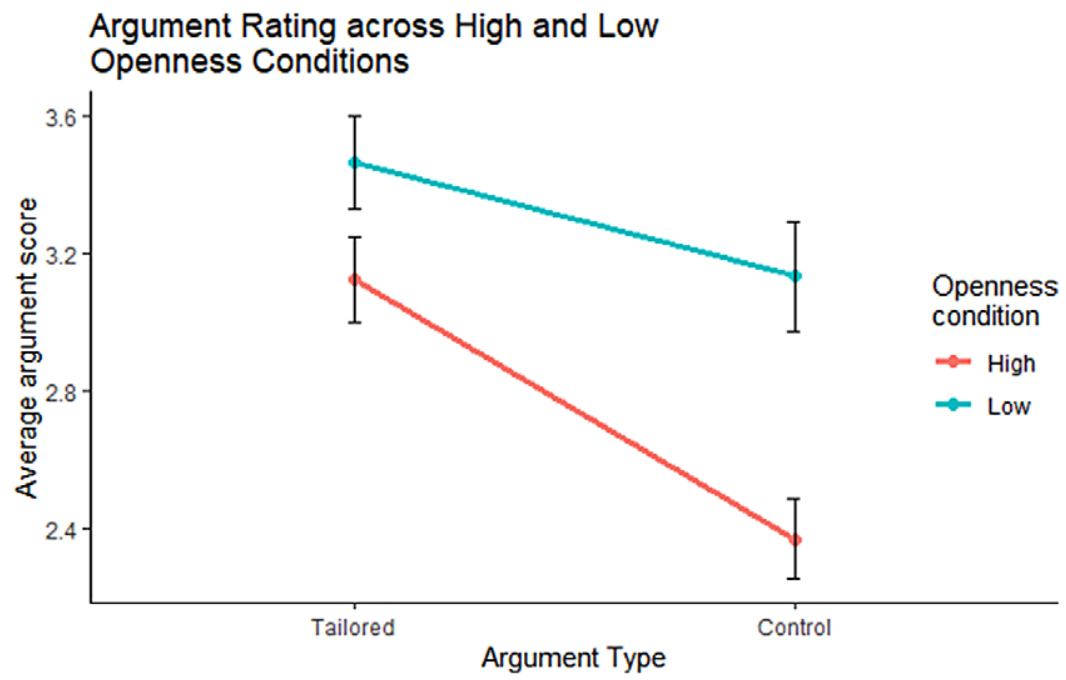

Walker Fig 4. - Mean argument rating of high and low Openness groups across the tailored and non-tailored arguments. (Error bars denote standard errors).

Independent $\mathrm{t}$-tests indicated there was no significant differences across the tailored arguments: credibility, $t(165.56)=-.62, p=.53, d=-.09$, compellingness, $t(176.7)=-.50, p=.61, d=-.07$ and vote intention, $t(181.73)=-1.18, p=.24, d=-.16$.

On the non-tailored control argument there were no significant difference in terms of credibility, $t(160.7)=-.62, p=.54, d=-.09$ or compellingness, $t(138.31)=-2.08, p=.04, d=-.32$. There was a significant difference in terms of vote intention with those low on Openness displaying a greater intention to vote, $t(140.85)=-3.02, p<.01, d=-.46$ than those high on Openness.

\section{Discussions}

Across all four traits there was either no or weak evidence for the interaction between targeting and tailoring. There were however clear effects of targeting, such that participants high or low on a trait rated arguments differently in a manner consistent with that traits association with more liberal or conservative politics. The strength and consistency of these differences differed substantially across traits.

The strongest and most consistent difference was between individuals high and low on Loyalty. This difference - showing a receptivity towards the arguments for those high in Loyalty - was a large effect for the arguments tailored towards Loyalty $(d=0.89-1.58)$ but also large for the non-tailored argument $(d=0.68-1.33)$, and there was no interaction. The lack of an interaction between targeting and tailoring for Loyalty suggests that whilst targeting might be effective, these results do not enable us to be certain that receptivity to the moral value of Loyalty is critical; this difference could be mediated by other psychological or demographic differences between these groups. It should be noted however that, whilst the non-tailored argument contained less references to Loyalty, it did contain some (for example to 'British students'), which may have been sufficient to appeal to participants high on Loyalty. 
Conscientiousness was the only trait where participants in the high compared to low groups displayed a difference between the tailored and the non-tailored arguments across the pairwise comparisons. Those high compared to those low on Conscientiousness showed a consistent receptivity towards the tailored arguments whilst showing no differences across the non-tailored control argument. This combination of differences is at least consistent with the idea that personality-based argument tailoring can influence political-based decision-making. However, the absence of a significant interaction effect cautions the veracity of this interpretation. Detecting interaction effects often requires more power however, so the pattern of pairwise comparisons suggests this result is worth testing with a larger sample.

Participants high on Fairness consistently rated the Leave arguments as less persuasive than those low on Fairness across the tailored and non-tailored arguments. Participants high on Openness (compared to low) only differed in their evaluation of one outcome (vote intention) for the non-tailored argument showing less receptivity towards it. For both Fairness and Openness there was no interaction. The lack of hypothesised effects across the Fairness and Openness conditions suggests that argument tailoring is particularly unlikely to prove effective in the absence of thoughtful targeting. In this instance the lack of an effect for Fairness and Openness could reflect the incongruence between the public discourse surrounding the Leave position and these psychological constructs.

Finally, it should be noted, all of these arguments were tested using arguments for Leaving the EU presented to Remain supporting participants. It would clearly be informative to extend this test to Leave supporting participants with arguments in favour of Remaining. Previous literature has highlighted associations between Loyalty and Conscientiousness and conservativism, and Openness and Fairness with liberalism, so the pattern of targeting effects found here should theoretically be reversed when making arguments for Remaining in the EU.

\section{Conclusions}

The results reveal that participants high or low on different traits respond differently to arguments for Leaving the EU. Some of these differences are large, with Remain supporters high on Loyalty consistently finding arguments much more persuasive than Remain supporters low on Loyalty. Some of these differences are more marginal, with participants high on Openness finding arguments for Leaving less persuasive than participants low on Openness only in one instance. Across all of the traits however there is no convincing evidence that the combination of targeting and tailoring is effective. The only potential exception is the case of Conscientiousness, in which participants high on this trait (compared to low) found the tailored arguments more persuasive but showed no difference on the non-tailored argument. Even in this case however the interaction between personality trait and message tailoring was not significant. Thus the results show substantive evidence for psychological targeting, but weak or no evidence for psychological targeting and tailoring.

Author Contributions. CW, SON and LdW conceived and designed the study. CW and SON conducted data gathering and performed statistical analyses. CW, SON and LdW wrote the article.

Funding Information. This research received no specific grant from any funding agency, commercial or not-for-profit sectors.

Data Availability Statements. All the research data and materials required to replicate this study are available at https://osf.io/ $\mathrm{fd} 29 \mathrm{~m} /$.

Ethics. The authors assert that all procedures contributing to this work comply with the ethical standards of the relevant national and institutional committees on human experimentation and with the Helsinki Declaration of 1975, as revised in 2008.

Conflicts of Interest. Conflicts of Interest: Christopher Walker, Stephen O’Neill and Lee de-Wit declare none.

Supplementary Materials. To view supplementary material for this article, please visit http://dx.doi.org/10.1017/exp.2020.43. 


\section{References}

Ekstrom, P. D., \& Federico, C. M. (2019). Personality and political preferences over time: Evidence from a multi-wave longitudinal study. Journal of Personality, 87, 398-412.

Feinberg, M., \& Willer, R. (2013). The moral roots of environmental attitudes. Psychological Science, 24, 56-62. https://doi.org/ $10.1177 / 0956797612449177$.

Feinberg, M., \& Willer, R. (2015). From Gulf to bridge: When do moral arguments facilitate political influence?. Personality and Social Psychology Bulletin, 41, 1665-1681. https://doi.org/10.1177/0146167215607842.

Gerber, A. S., Huber, G. A., Doherty, D., Dowling, C. M., \& Ha, S. E. (2010). Personality and political attitudes: Relationships across issue domains and political contexts. American Political Science Review, 104, 111-133. https://doi.org/10.1017/ S0003055410000031.

Graham, J., Haidt, J., \& Nosek, B. A. (2009). Liberals and conservatives rely on different sets of moral foundations. Journal of Personality and Social Psychology, 96, 1029-1046. https://doi.org/10.1037/a0015141.

Hatemi, P., Medland, S., Klemmensen, R., Oskarrson, S., Littvay, L., Dawes, C., Verhulst, B., McDermott, R., Nørgaard, A. S., Klofstad, C. A., Christensen, K., Johannesson, M., Magnusson, P. K. E., Eaves, L. J., \& Martin, N. (2014). Genetic influences on political ideologies: Twin analyses of 19 measures of political ideologies from five democracies and genomewide findings from three populations. Behavioral Genetics, 44, 282-294. https://doi.org/10.1016/j.devcel.2010.12.007. Peroxiredoxin.

Hirsh, J. B., Kang, S. K., \& Bodenhausen, G. V. (2012). Personalized persuasion: Tailoring persuasive appeals to recipients' personality traits. Psychological Science, 23, 578-581. https://doi.org/10.1177/0956797611436349.

Matz, S. C., Kosinski, M., Nave, G., \& Stillwell, D. J. (2017). Psychological targeting as an effective approach to digital mass persuasion. Proceedings of the National Academy of Sciences, 114, 12714-12719. https://doi.org/10.1073/pnas.1710966114.

Sibley, C. G., Osborne, D., \& Duckitt, J. (2012). Personality and political orientation: Meta-analysis and test of a threatconstraint model. Journal of Research in Personality, 46, 664-677. https://doi.org/10.1016/j.jrp.2012.08.002.

Voelkel, J. G., \& Feinberg, M. (2018). Morally reframed arguments can affect support for political candidates. Social Psychological and Personality Science, 9, 917-924. https://doi.org/10.1177/1948550617729408.

Cite this article: Walker C, O’Neill S, de-Wit L (2020). Evidence of Psychological Targeting but not Psychological Tailoring in Political Persuasion Around Brexit Experimental Results, 1, e38, 1-13. https://doi.org/10.1017/exp.2020.43 


\title{
Peer Reviews
}

\author{
Reviewing editor: Prof. Eve Isham \\ University of Arizona, Department of Psychology, Tucson, Arizona, United States, 85721-0001
}

This article has been accepted because it is deemed to be scientifically sound, has the correct controls, has appropriate methodology and is statistically valid, and has been sent for additional statistical evaluation and met required revisions.

doi:10.1017/exp.2020.43.pr1

Review 1: A preliminary test of Personality and Moral Foundation based Argument Tailoring in Political Persuasion around Brexit.

Reviewer: Dr. Pierce Ekstrom

Washington University in Saint Louis, Department of Psychological \& Brain Sciences, Saint Louis, Missouri, United States, 63130-4899

Date of review: 22 February 2020

(c) The Author(s), 2020. Published by Cambridge University Press This is an Open Access article, distributed under the terms of the Creative Commons Attribution licence (http://creativecommons.org/licenses/by/4.0/), which permits unrestricted re-use, distribution, and reproduction in any medium, provided the original work is properly cited.

Conflict of interest statement. Reviewer declares none

Comments to the Author: Please forgive my curtness. I only have 250 words.

The study topic is interesting and I think the paper can be revised to make an effective contribution. Some additional details are needed, and some reframing may be appropriate.

-Why dichotomize the moral foundation scores and personality? Can continuous scores be used?

-MFQ scores and personality are observed, not manipulated. The primary IV should be message tailoring. Mixed ANOVAs should take center stage, even if post-hoc; the experimental component of the design is really within-, not between-subjects. The Wilcoxon rank-sum tests are correlational and indicate only that participants who valued loyalty above all else responded more favorably to proBrexit arguments (still an interesting finding).

-All variables should be more clearly defined in the main paper or appendix if space allows. It's unclear how predictors were "abbreviated" and how the DVs were assessed. Of the outcomes, "vote intention" sounds like it could be a non-directional turnout variable, but I assume that's not the case. Can we also get alphas for the predictors?

-Because MFQ scores and personality are observed, not manipulated, Wilcoxon ranked sum analyses are subject to omitted variable bias. Can authors supplement with analyses that control for ideology or related variables? For example, participants who valued loyalty may have responded favorably to all the pro-Leave arguments not because they valued loyalty per se, but because they were more conservative (or less liberal) than participants who valued loyalty least. Results could imply merely that moderates are more persuadable. 
Presentation

Is the data presented in the most useful manner? (40\%) 2/5

Does the paper cite relevant and related articles appropriately? (30\%) 4/5

\section{Context}

Does the abstract correctly embody the content of the article? (25\%)

Does the introduction give appropriate context? (25\%)

Is the objective of the experiment clearly defined? (25\%)

Analysis

Are the limitations of the experiment as well as the contributions of the experiment clearly outlined? $(20 \%)$ 


\title{
Review 2: A preliminary test of Personality and Moral Foundation based Argument Tailoring in Political Persuasion around Brexit.
}

\author{
Reviewer: Prof. Peter Ayton (i)
}

City University, Department of Psychology, United Kingdom of Great Britain and Northern Ireland

Date of review: 18 June 2020

\begin{abstract}
(c) The Author(s), 2020. Published by Cambridge University Press This is an Open Access article, distributed under the terms of the Creative Commons Attribution licence (http://creativecommons.org/licenses/by/4.0/), which permits unrestricted re-use, distribution, and reproduction in any medium, provided the original work is properly cited.
\end{abstract}

Conflict of interest statement. Reviewer declares none

Comments to the Author: The abstract could be clearer regarding the empirical findings - can't you be more explicit about what you found here?

How were the four hypotheses chosen - what was the basis for THESE values and traits being selected?

H4 refers to consciousness - this should be conscientiousness - yes?

How were the Remain supporting participants recruited - and why were their counterparts so hard to recruit?

The design of each study is hard to discern - participants were assigned to each condition based on their scores - not randomly - how and why? Given that they either saw arguments tailored one way or the other, random allocation seems reasonable. The primary statistical outcome was a between-participants test of whether participants high on a given moral foundation or personality trait rated the arguments differently from those low on the same trait - but the paper reports that "...individuals in the high Loyalty condition differed significantly on the tailored arguments..." Differed significantly from those in the low Loyalty condition? If so please say so. But that's confusing: they were ASSIGNED to Loyalty or Fairness conditions - not high or low loyalty - that was simply determined by their test score surely?

Nonparametric tests were used - why? And then - sometimes a (parametric) ANOVA. Why the two? And why, given the evident suitability of the data for parametric analysis weren't interactions in ANOVA the default analysis for assessing differential susceptibility to tailored arguments?

\section{Score Card}

Presentation

Is the article written in clear and proper English? (30\%)

Is the data presented in the most useful manner? (40\%)

Does the paper cite relevant and related articles appropriately? (30\%)

\section{Context}

Does the title suitably represent the article? (25\%)

Does the abstract correctly embody the content of the article? (25\%)

Does the introduction give appropriate context? (25\%)

Is the objective of the experiment clearly defined? (25\%) 
Analysis

Is the conclusion consistent with the results and discussion? (40\%)

Are the limitations of the experiment as well as the contributions of the experiment clearly outlined? (20\%) 
Review 3: A preliminary test of Personality and Moral Foundation based Argument Tailoring in Political Persuasion around Brexit.

Reviewer: Dr. Jason Harman (iD

Louisiana State University System, Psychology, 236 Audubon Hall, Baton Rouge, Louisiana, United States, 70803

Date of review: 18 June 2020

Conflict of interest statement. reviewer declares none

Comments to the Author: The incremental work presented points to the need for further study particularly in terms of generalizability. It is unfortunate that there isn't data on leave voters as this would be needed to have confidence that conscientiousness itself (and not an interaction between conscientiousness and environment) is a driver in the modest effects found.

\section{Score Card}

Presentation

4.3

Is the article written in clear and proper English? (30\%)

Is the data presented in the most useful manner? (40\%)

Does the paper cite relevant and related articles appropriately? (30\%)

Context

Does the abstract correctly embody the content of the article? (25\%)

Does the introduction give appropriate context? (25\%)

Is the objective of the experiment clearly defined? (25\%)

Analysis

Are the limitations of the experiment as well as the contributions of the experiment clearly outlined? (20\%) 